\title{
Studying and Optimizing the Effect of Process Parameters on Machining Vibration in Turning Process of AISI 1040 Steel
}

\author{
Adel Al-Shayea, ${ }^{1}$ Fawaz M. Abdullah, ${ }^{1}$ Mohammed A. Noman $\mathbb{D}^{1,2}$ Husam Kaid ${ }^{10},{ }^{1,2}$ \\ and Emad Abouel Nasr $\mathbb{1}^{1,3}$ \\ ${ }^{1}$ Industrial Engineering Department, College of Engineering, King Saud University, P.O. Box 800, Riyadh 11421, Saudi Arabia \\ ${ }^{2}$ Department of Industrial and Manufacturing Systems Engineering, College of Engineering \& IT, Taiz University, Taiz 6803, \\ Yemen \\ ${ }^{3}$ Faculty of Engineering, Mechanical Engineering Department, Helwan University, Cairo 11732, Egypt
}

Correspondence should be addressed to Mohammed A. Noman; mmohammed1@ksu.edu.sa

Received 5 June 2020; Revised 12 July 2020; Accepted 4 August 2020; Published 30 August 2020

Academic Editor: Aniello Riccio

Copyright (c) 2020 Adel Al-Shayea et al. This is an open access article distributed under the Creative Commons Attribution License, which permits unrestricted use, distribution, and reproduction in any medium, provided the original work is properly cited.

\begin{abstract}
The turning, which consists of the removal of metal from the outer diameter of a rotating cylindrical workpiece, is one of the most common techniques for cutting, especially when finishing the product. The values of the cutting parameters, such as feed rate, cutting speed, and depth of cut, in a turning operation must be selected carefully to improve the profit of operations by enhancing productivity and reducing the total manufacturing cost for each component. A high vibration leads to poor surface finish and reduced productivity and shortens the tool life; therefore, this parameter should be controlled. In this study, an experiment is conducted to investigate the effects of these cutting parameters in the turning process of a workpiece, composed of AISI 1040 steel, using the response surface method. Statistical tools were used to design the experiments. These parameters are optimized by using analysis of variance, regression, and optimization techniques to achieve the condition of minimum vibration and chip frequency, therefore improving the surface roughness after the turning process.
\end{abstract}

\section{Introduction}

Machining processes, such as turning, milling, and drilling, are important in manufacturing industries. Turning is a process in which the metal from the outer diameter of the rotating cylindrical workpiece is removed, reducing the diameter of the workpiece, usually to a specific dimension, with a smooth finish on the metal. In manufacturing studies, vibration is one of the main issues that is bounded to machining processes. Vibration is an unavoidable phenomenon in machining that affects the quality of the product, machining accuracy, cutting tool, and machine tool life, increasing operation cost.

The goal of the industry has always been the manufacturing of low-cost and high-quality products in a short time. Modern industries try to enhance these characteristics. To achieve a high cutting performance, the industry needs to operate close to the optimal cutting parameters [1]. Consequently, cutting conditions such as feed rate, speed, and depth of cut in the turning process must be selected appropriately to improve productivity, reduce the total manufacturing cost for each component, or achieve a predefined appropriate criterion. Because of the high cost of digitally controlled machine tools, when compared with their traditional counterparts, their operation is required to be efficiently conducted to manufacture the required product [2].

In the turning process, vibrations occur because of friction between the workpiece and the tool. Consequently, the performance of the machine depends heavily on vibration cutting processes, in which a vibration-free scenario is ideally desired. The rate of deterioration and inaccuracy that increase with the usage of the machine tool can be determined by monitoring vibration [2]. Theories of 
coupling situation are theories of vibration that have become prominent [3]. Wiercigroch and Budak [4] stated that the coupling situation, resulting from the vibration in the direction of momentum, generates the vibration in the direction of the cutting force and vice versa, leading to a multidirectional path (in the directions of the cutting thrust and cutting). Hamdan and Bayoumi [5] suggested that the increase in the rake angle and flank clearance has increased the stability of the dynamic cutting process because of variation effects. Moreover, a mathematical model, a linear differential equation suitable for cutting speeds, low and high dynamic processes of cutting (considering the frictional force on the flank), and the tool of the tool rake have also been proposed. Moreover, these parameters have affected the strength of the initial friction.

Dimla [6] proposed that the tool wear directly affects the bad edge caused by the vibration of the tool, which is, thereafter, increased. Because of the plastic deformation, the high value of tool vibration leads to a decrease due to the linear increase of the contact area. Meanwhile, Dimla [7] investigated the effect of the cutting conditions on the cutting forces and vibrations resulting from the wear of the cutting tool. The results show that variations in cutting conditions affect the cutting forces and vibration signals. Furthermore, Asiltürk and Akkuş [8] suggested that the feed rate and depth affect the stability of the machines, increasing the vibration and resulting in the bad finishing of the surface. Moreover, the increase in speed led to a reduction in the vibration, improving the stability of the manufacturing process.

Accelerometers are commonly used as a sensor for recording vibration signals. Dan and Mathew [9] proposed vibration control techniques [10-14] that are more practical and cost-effective and discussed their limitations and advantages. Sick [15] also reviewed various vibration control techniques to predict the flank wear [16-18] at the preprocessing level.

Ambhore et al. [19] developed a mathematical prediction model to determine vibration acceleration and surface roughness with specific machining parameters such as cutting speed, feed rate, and cutting depth. The results show that the conditions under which the vibration signal is cut have a significant mixed effect. For the estimation of vibration and surface roughness, the regression model was found to be appropriate. Sofuoğlu et al. [20] used an advanced machining method to research the effects of cuts, cutting velocity and tool overhang lengths, surface ruggedness, stable cuts depth, and tool temperature in turning operations of Hastelloy-X alloys. Çakır et al. [21] studied the machining characteristics of Hastelloy-X and developed a numerical model for the turning of Hastelloy-X. The operation varied from two input parameters (cutting speed and feed rate) to results based on process outputs such as cutting forces, cutting temperature, effective stresses, and chip morphology. The results were evaluated. The results showed that the model was appropriate for turning Hastelloy-X at low and medium speeds of processing. Sofuoğlu et al. [22] carried out 2D finite element (FE) analysis to investigate the effects of these machining methods on titanium and Hastelloy-X alloys in terms of cutting forces, cutting tool temperatures, and effective stresses. DEFORM-2D software was used during analyses. They confirmed that the hot ultrasonic-assisted turning technique reduces cutting forces and effective stress significantly but cutting temperature increases compared to conventional and ultrasonic-assisted turning. A new method of multicriteria decision-making (MCDM) has been developed by Gürgen et al. [23], to investigate the various turning procedures (conventional, ultrasonic-assisted, and hot ultrasonic-assisted) of Ti6Al4V alloy. According to MCDM results, higher cutting speeds, lower tool overhang lengths, and ultrasonic-assisted turning are the appropriate levels of the cutting parameters. The findings have contributed to understanding the MCDM experience of modern nontraditional methods of machining. Parida et al. [24] studied the effect of microdimple-textured tool in turning of Ti6Al4V alloy which is assessed by considering cutting force, chip morphology, and chip flow angle using the finite element method (FEM). The proposed 3D FE model helps in reducing the number of experimental trials that require optimizing the machining process.

The turning process of Inconel 718 was investigated in a study by Guergen et al. [25] in terms of workpiece surface quality and the wear behavior of cutting tools. The study showed the correlation between input and output parameters such as feed rate, insert nose radii, and the insert of coating methods. The analysis gave short results for the proper selection of instruments in Inconel 718's turning process. In the study of Şahinoğlu and Rafighi [26], turning tests were conducted on three different hardened AISI 1040 steels at three different cutting depths, feeding rates, and noncoolant cutting speeds. The study aimed mainly at minimizing both surface ruggedness and power consumption by estimating optimized machining parameters. The effects of cutting parameters and workpiece hardness on surface roughness, sound level, and power consumption were examined. The findings showed that the feed rate was the most significant machining parameter affecting surface roughness and power consumption. The depth of cut and cutting speed also have significant effects following the feed rate.

The study of Haque et al. [27] found that feed rate, depth of cut, and cutting condition with water are the most significant factors affecting the surface roughness for turning of AISI 1040 steel. Prakash and Krishnaiah [28], Pavani et al. [29], and Nair et al. [30] studied the effect of cutting speed, feed rate, and depth of cut on surface roughness for turning of AISI 1040 steel. However, Nair et al. [30] suggested the same three factors to study the effect of tool vibration on flank wear and surface roughness during high-speed machining of 1040 steel. Kumar et al. [31] carried out Taguchi's experimental design to obtain the effect of cutting force, cutting tool temperature, and tool flank wear on surface roughness in turning of AISI 1040 steel.

In this work, the response surface method (RSM) was used to obtain the optimal value of response variables (vibration and chip frequency). RSM is a useful set of mathematical and statistical techniques for modeling and analyzing the effects of any variable on a specific problem, to improve the response, as conducted by Montgomery [32]. RSM is widely used in process improvement experiments 
regarding the turning process. Gaitonde et al. [33] analyzed the effects generated by the depth of the cut and machining time with this method in the turning of AISI D2 cold work tool steel. Moreover, by using the RSM, Asiltürk and Neseli [34] obtained a model for the surface roughness, as a function of the cutting parameters, and analyzed the impact of these parameters on the surface quality. CamposecoNegrete [35] optimized variables related to the turning of AA 6061 T6 to obtain the conditions for the minmum energy consumption. Bhushan [36] used the RSM analysis to investigate the effects of the cutting parameters in the turning of $\mathrm{SiC} 7075 \mathrm{Al}$ alloy to reduce the energy consumption of the machine and increase the life of the tool.

According to the literature review, the RSM has been proved to be practical and effective; therefore, it was used in this research to determine the effects of parameters of the turning process on the surface roughness. Furthermore, previous research concluded that the selection of the cutting parameters is essential for machining, especially in the turning process; however, the combination of multiple effects from different parameters on vibration and chip frequency has not been considered yet for the turning process. An experiment was, therefore, conducted to investigate the effects of depth of cut, cutting speed, and feed rate in the turning process of the AISI 1040 steel using RSM.

It can be seen from the literature that few papers have been reported on the optimization of the factors affecting vibration characteristics of turning process of AISI 1040 steel by using RSM in terms of experimental and mathematical analysis. Furthermore, none of the papers considers the combination of the effect of the real conditions such as cutting speed, feed rate, and depth of cut to study the vibration and chip frequency simultaneously by applying the statistical analysis and heuristic methods. Therefore, this study has contributed to studying the effect of cutting speed, feed rate, and depth of cut on vibration and chip frequency simultaneously in turning of AISI 1040 steel using RSM, and it found the optimized parameters using two heuristic algorithms.

The methodology used to investigate the parameter optimization of the turning process of the AISI 1040 steel using the RSM is shown in Figure 1. Furthermore, the proposed methodology steps are defined as follows:

Step 1: literature review on the turning process, vibration on machining, RSM, and required terms.

Step 2: designing of the experiment. In this step, the RSM is designed to evaluate the effects of parameters on the surface roughness after the turning process.

Step 3: experimental processes consist in selecting the appropriate material, which is AISI 1040 steel, and executing the turning process using a Harrison M390 machine.

Step 4: data analysis using the RSM to optimize the parameters of the turning process.

Step 5: results and discussion to verify if the implementation of the experiment was satisfactory.

\section{Experimental Setup for Machining}

2.1. Material. In this research, a commercial and commonly used AISI 1040 steel [26, 30, 37], whose chemical composition and mechanical properties are shown in Table 1, was used.

2.2. Mounting Workpiece on Lathe Machine. The experiment has been implemented using a lathe machine Harrison M390, as shown in Figure 2, which has $5.5 \mathrm{~kW}$ of nominal power and $2000 \mathrm{rpm}$ of maximum spindle speed. The material of the workpiece was a medium AISI 1040 steel, as described in the previous section. The length and diameter of the workpiece were 500 and $100 \mathrm{~mm}$, respectively.

The workpiece was placed on the tailstock, which needed more support, as the spindle bearings could be harmful to the experiment because of the heaviness of the workpiece. After completing the setup of the lathe machine, the surfacing of the workpiece was conducted to eliminate the outer layer of the workpiece, which was rusty, as shown in Figure 3.

2.3. Tool Holder and Insert. Figure 4 shows the selected insert, which is in the steel cutting grade. Moreover, tungsten carbide and titanium carbide of the insert bound together because of cobalt, CO. The insert was made with facecentered cubic structures to enhance the cutting speed and precision of the process, therefore improving the smoothness of the workpiece. Because of their unique properties, such as low friction and high resistance against crack, diffusion, and wear, coated tools can be used at high cutting speeds, reducing the time and cost required for machining operations.

After the insert was clamped to the tool holder, the clamp was tightened with a clamp screw, as shown in Figure 5. Two contcgqzurations of tool overhang (70 and $120 \mathrm{~mm}$ ) were used. Afterward, the tool holder was tightened on the turret and the cutting tool was accurately centered, considering the center of the tailstock tip, to avoid imprecision problems in the process, which could hinder the smoothness of the final workpiece.

\section{Design of the Experiment Using RSM}

The RSM was used to estimate the significance of the effects of the process parameters considering the surface roughness. Speed, feed rate, and depth of cut, which are independent variables, were selected as these parameters based on the RSM methodology and according to the previous literature. Figure 6 shows the dependence relationship between the independent variables and dependent variables (vibration and chip frequency variables), which are essential to analyze the surface roughness. The expertise of the user is classified as a moderate variable which has a strong contingent effect on the relationship of the variables. By contrast, the accuracy is used as a mediating variable that influences the results.

In this research, central composite design (CCD) was the methodology chosen to design the experiment. This 


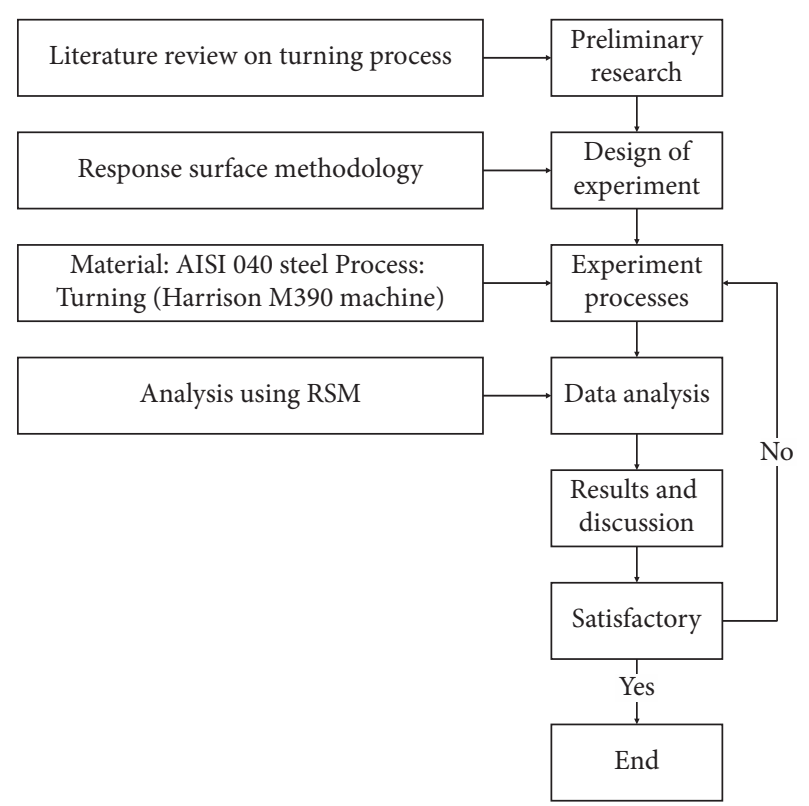

FIGURE 1: Flow chart of the proposed methodology.

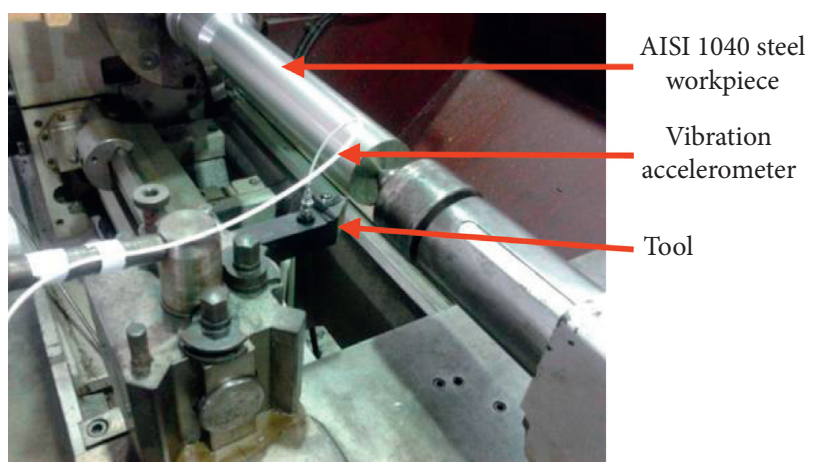

FIGURE 2: Mounting workpiece on the lathe machine.

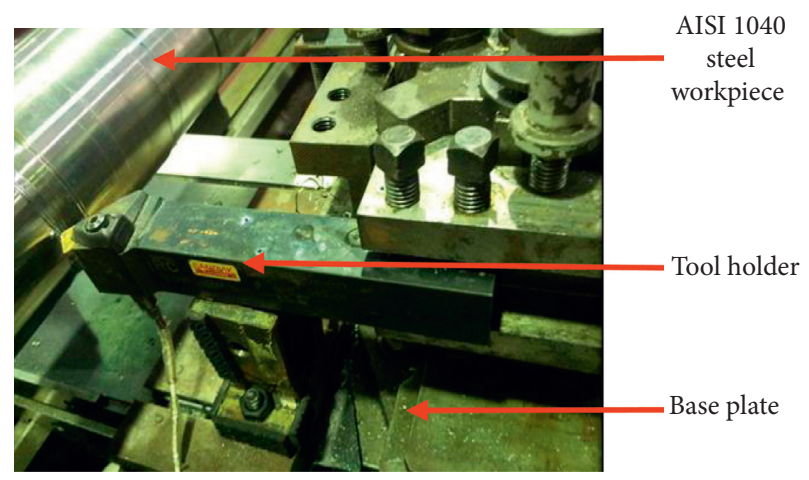

FIgURE 3: Surfacing the workpiece.

methodology can be coupled with RSM to build a quadratic model for the variable response.

The CCD is the most popular among the categories of RSM design because of the following reasons:

(i) CCD can be divided into two group analyses that represent different effects and, therefore, can be
Table 1: Properties of AISI 1040 steel [37].

\begin{tabular}{lc}
\hline Element & $\%$ \\
\hline Chemical composition & \\
Iron, Fe & $98.6-99$ \\
Manganese, Mn & $0.60-0.90$ \\
Carbon, C & $0.370-0.440$ \\
Sulfur, S & $\leq 0.050$ \\
Phosphorous, P & $\leq 0.040$ \\
\hline Mechanical properties & \\
Tensile strength & $620 \mathrm{MPa}$ \\
Yield strength & $415 \mathrm{MPa}$ \\
Elastic modulus & $190-210 \mathrm{GPa}$ \\
Poisson's ratio & $0.27-0.30$ \\
Elongation at break (in $50 \mathrm{~mm}$ ) & $25 \%$ \\
\hline
\end{tabular}

individually performed. The first one estimates the linear effect, and the second one estimates the curvature effect. Consequently, when the analysis data points of the first subset have no significant curvature effect, for example, the second subset is not required.

(ii) CCD is effective, as it provides information on experiment variables and overall experimental error with minimum required interactions.

(iii) CCD can be used in various experimental areas. CCD contains a design factorial or fractional factorial of the central points that are supported with a set of optimum points, allowing an accurate estimation of the curvature.

In CCD, two types of experimental designs can be chosen (full or small). For this experiment, the small CCD was chosen, as shown in Table 2.

3.1. Vibration Detector Setup. The easy-to-use DasyLab was applied to easily and quickly analyze vibration data by working with a display directly on the screen. An accelerometer was used to sense and obtain vibration data. The accelerometer will be placed on the part to be tested. Accelerometers are installed using special wax because they were a good mounting tool for lightweight sensors in temporary installations. The wire connected to the accelerometers must be properly connected to support the wire weight, as shown in Figure 7(a). Unit icons were placed on the screen and connected to wires in a diagram representing the flow of data across the system. In this case, the vibration sensor was connected to the tool holder and connected to the computer. The captured and analyzed signal was further adapted using the DasyLab 5.6 software in the Fast Fourier transformation (FFT) field, as shown in Figure 7(b). From the FFT plots of the vibration data (the sample is shown in Figure 7)(b), the vibration amplitude was easily determined from the program. The dynamics of the turning process is as follows: the tangential or cutting force runs down at the tip of the tool allowing the workpiece to deviate upward, the feed rate of 


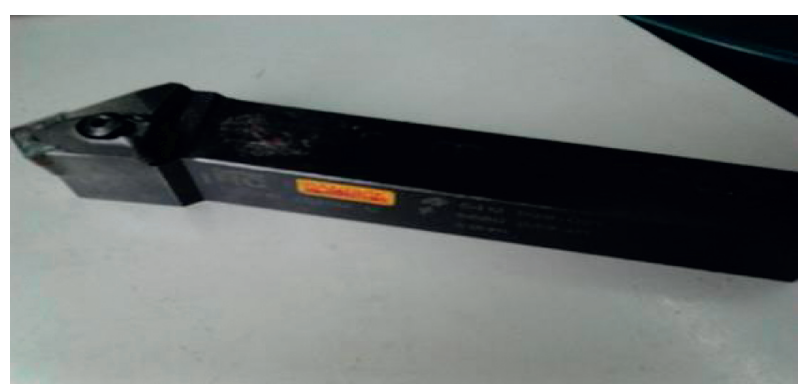

Figure 4: Geometric shape of the tool holder.

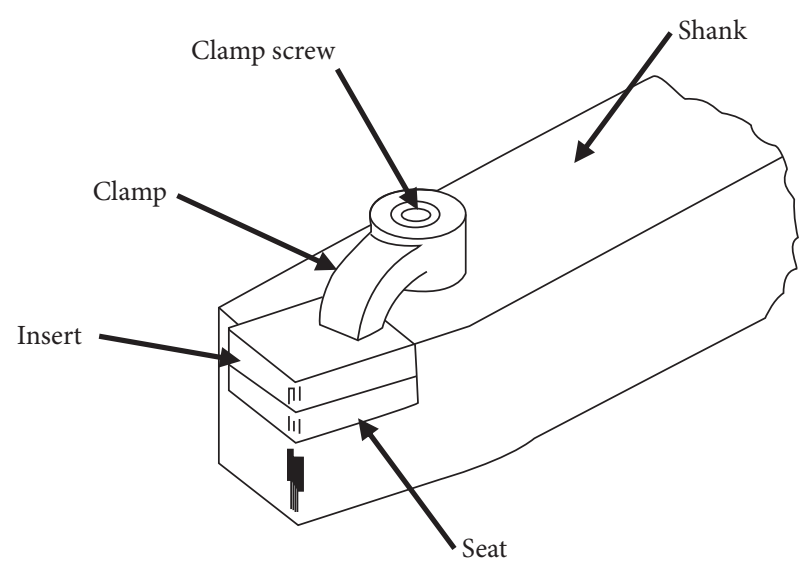

FIgURE 5: Tool holder illustration.

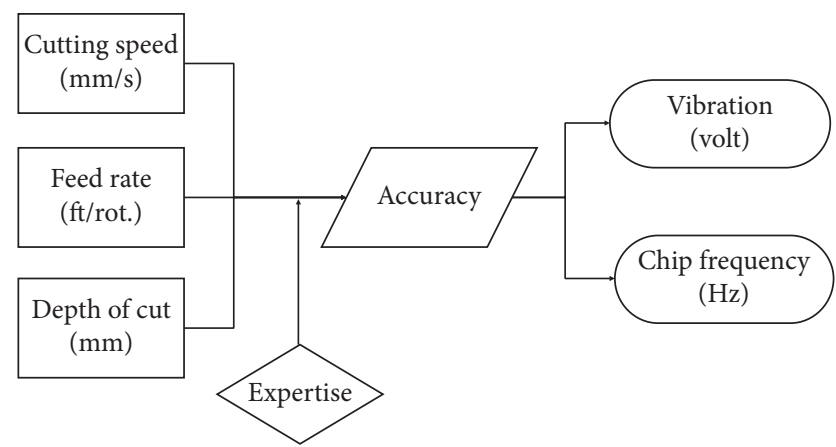

Figure 6: The relationship between the variables.

axial force works in the longitudinal direction, the thrust or radial force works in the radial direction and tends to push the tool away from the workpiece [38].

\section{Results and Discussion}

This section provides the RSM results based on the measurements of vibration and chip frequency. Furthermore, their relation with the cutting parameters is quantified with interaction, main effect, and surface plots. Moreover, mathematical models and optimization are presented. Table 3 presents the configuration of the experiments and the vibration and chip frequency results.

\subsection{Development of Vibration Model}

4.1.1. Analysis of Variance. The analysis of variance, shown in Table 3, indicates that the model is adequate as the $p$ value of the model is lower than 0.05 ; therefore, the terms selected to compose the model, such as cutting speed $(\mathrm{mm} / \mathrm{s})$, depth of cut (mm), feed rate (ft/rot), $A^{2}, B^{2}, C^{2}, A B, A C$, and $B C$, could represent the behavior of the vibration. Consequently, the model could accurately predict the vibration behavior because of the high value of $R$-sq. (adj) (99.98\%). $R$-squared is a statistical measure that shows the proportion of the variance for a dependent variable which is explained by an independent variable or variables in a regression model.

The estimated regression coefficients for vibration, which are presented in Table 4, indicate that their values were significantly different. The main effects can be seen from the $p$ value, so if the value is less than 0.05 , it can be said that the result is significant. Furthermore, the cutting speed, depth of cut, and feed rate are significant to the response model at 0.05 .

4.1.2. Residual Plots for Vibration. Figure 8 shows the residual plots against the percentage and fitted values, the frequency in the dataset, and the observation index. The results were distributed randomly based on the fitted values and observation index. Moreover, the results show that the $p$ value of the residuals (0.223) was higher than 0.05 for the vibration. A linear relation is observed when the residuals are plotted against the percent values.

Table 5 shows the contributions of each cutting parameter and their combinations that have been calculated from equation (1). The combination of cutting speed and depth of cut had the highest contribution for vibration, followed by the depth of cut and feed rate, cutting speed, depth of cut, cutting speed and feed rate, and feed rate:

$$
\text { contribution }=\frac{\text { adjusted sum of squares for each factor }}{\text { total adjusted sum of squares }} \text {. }
$$

4.1.3. Interaction Plot for Vibration. Figure 9 shows the influences of the depth of cut and the feed rate on the vibration. Consequently, the increase of depth of cut $(B)$ and/ or feed rate $(C)$ contributes to the increase of vibration. The interaction between feed rate and depth of cut, as shown in Figure 9, also influences the vibration.

4.1.4. Contour Plot for Interaction Factor. Figure 10 displays the vibration contours at all different combinations of cutting speed parameters. Consequently, the increase in depth of cut led to an increase in vibration increased. 
TABLE 2: Design of the experiments and results of vibration and chip frequency.

\begin{tabular}{|c|c|c|c|c|c|c|}
\hline Std order & Run order & Cutting speed $(\mathrm{mm} / \mathrm{s})$ & Depth of cut (mm) & Feed rate $(\mathrm{ft} / \mathrm{rot})$ & Vibration (Volt) & Chip frequency $(\mathrm{Hz})$ \\
\hline 1 & 1 & 50 & 2 & 0.22 & 0.091 & 2099.8 \\
\hline 12 & 2 & 50 & 1.5 & 0.16 & 0.0702 & 1005.3 \\
\hline 3 & 3 & 200 & 1.5 & 0.16 & 0.157 & 6980.2 \\
\hline 8 & 4 & 125 & 1.5 & 0.8 & 0.10631 & 7291.1 \\
\hline 6 & 5 & 125 & 0.79 & 0.16 & 0.07371 & 9002.4 \\
\hline 11 & 6 & 125 & 2.21 & 0.16 & 0.1212 & 1144.06 \\
\hline 13 & 7 & 125 & 1.5 & 0.16 & 0.10253 & 5545.4 \\
\hline 7 & 8 & 125 & 1.5 & 0.16 & 0.10223 & 5466.1 \\
\hline 10 & 9 & 125 & 1.5 & 0.16 & 0.10235 & 5720.8 \\
\hline 15 & 10 & 125 & 1.5 & 0.16 & 0.10217 & 5512.3 \\
\hline 14 & 11 & 200 & 1 & 0.22 & 0.1308 & 6781.3 \\
\hline 4 & 12 & 200 & 2 & 0.1 & 0.1606 & 2215.18 \\
\hline 5 & 13 & 50 & 1 & 0.1 & 0.06 & 2022.3 \\
\hline 9 & 14 & 125 & 1.5 & 0.24 & 0.11875 & 1484.18 \\
\hline 2 & 15 & 125 & 1.5 & 0.16 & 0.10212 & 4925.4 \\
\hline
\end{tabular}
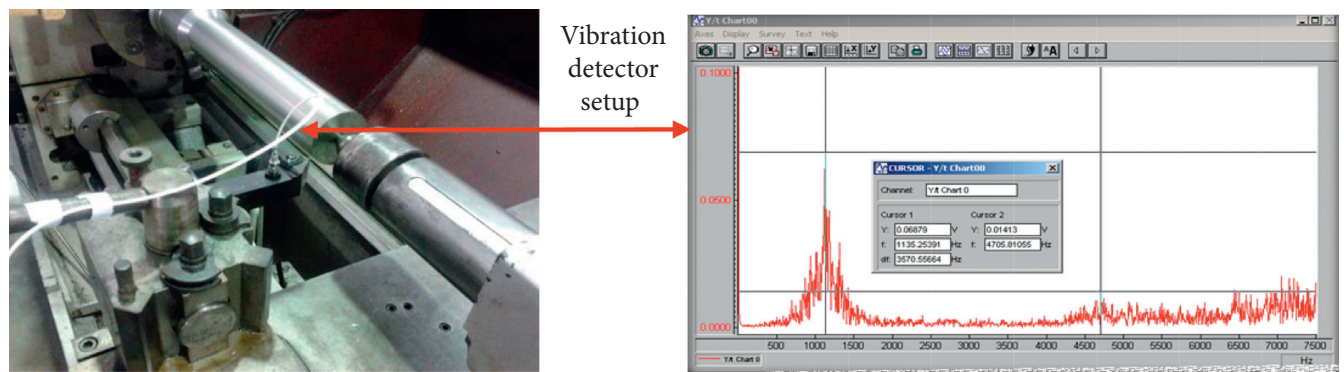

FIGURE 7: Vibration detector setup: (a) accelerometer setting and (b) FFT plot sample.

TABLe 3: Analysis of variance for vibration.

\begin{tabular}{|c|c|c|c|c|c|}
\hline Source & $\mathrm{DF}$ & Adj SS & Adj MS & $F$ value & $p$ value \\
\hline Model & 9 & 0.011317 & 0.001257 & 10367.38 & $\leq 0.001$ \\
\hline Linear & 3 & 0.000103 & 0.000034 & 282.21 & $\leq 0.001$ \\
\hline$A$ : cutting speed & 1 & 0.00008 & 0.00008 & 659.39 & $\leq 0.001$ \\
\hline$B:$ depth of cut & 1 & 0.000014 & 0.000014 & 115.37 & $\leq 0.001$ \\
\hline$C:$ feed rate & 1 & 0.000004 & 0.000004 & 34.86 & 0.002 \\
\hline Square & 3 & 0.000568 & 0.000189 & 1561.77 & $\leq 0.001$ \\
\hline$A^{\frac{1}{2}}$ & 1 & 0.000423 & 0.000423 & 3491.39 & $\leq 0.001$ \\
\hline$B^{2}$ & 1 & 0.000036 & 0.000036 & 298.67 & $\leq 0.001$ \\
\hline$C^{2}$ & 1 & 0.000218 & 0.000218 & 1797.23 & $\leq 0.001$ \\
\hline 2-way interaction & 3 & 0.000265 & 0.000088 & 727.19 & $\leq 0.001$ \\
\hline$A B$ & 1 & 0.000168 & 0.000168 & 1385.91 & $\leq 0.001$ \\
\hline$A C$ & 1 & 0.000005 & 0.000005 & 38.35 & 0.002 \\
\hline$B C$ & 1 & 0.000092 & 0.000092 & 757.32 & $\leq 0.001$ \\
\hline Error & 5 & 0.000001 & 0.000000 & - & - \\
\hline Pure error & 4 & 0.000000 & 0.000000 & - & - \\
\hline Total & 14 & 0.011317 & - & - & - \\
\hline Model summary & $S(0.00035)$ & $R$-sq. $(99.99 \%)$ & $R$-sq. (adj) $(99.98 \%)$ & - & - \\
\hline
\end{tabular}

4.1.5. Surface Plot for Vibration. Figure 11 displays a surface plot of the vibration based on the feed rate and depth of cut. The target vibration (red area) is achieved, therefore, at a low value of depth of cut and high value of feed rate.
4.1.6. Mathematical Model of Vibration. The vibration ( $V$ ) model obtained from the procedure in the previous section is represented in equation (2).

Vibration: 
TABLE 4: Estimated regression coefficients for vibration.

\begin{tabular}{lcc}
\hline Term & Coef. & $p$ value \\
\hline Constant & 0.08729 & $\leq 0.001$ \\
$A$ & -0.000548 & $\leq 0.001$ \\
$B$ & -0.02946 & $\leq 0.001$ \\
$C$ & -0.1088 & 0.002 \\
$A^{2}$ & 0.000002 & $\leq 0.001$ \\
$B^{2}$ & -0.009084 & $\leq 0.001$ \\
$C^{2}$ & -0.35627 & $\leq 0.001$ \\
$A B$ & 0.000367 & $\leq 0.001$ \\
$A C$ & 0.000338 & 0.002 \\
$B C$ & 0.2767 & $\leq 0.001$ \\
\hline
\end{tabular}
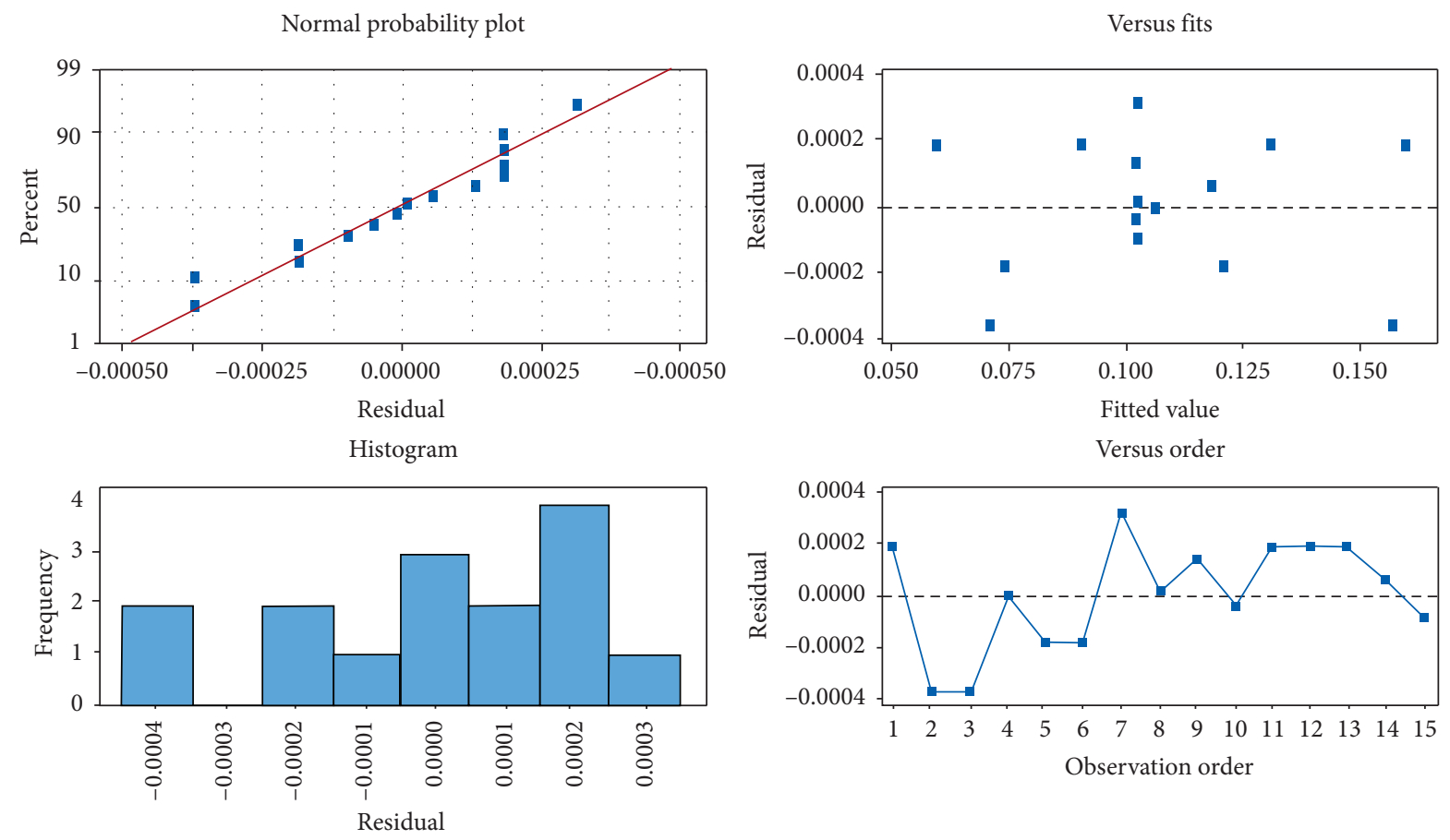

Figure 8: Residual plots for vibration (volt).

TABle 5: Percentage contribution for vibration.

\begin{tabular}{lc}
\hline Item & Percentage contribution \\
\hline$A$ & 22 \\
$B$ & 3.85 \\
$C$ & 1.1 \\
$A B$ & 46.2 \\
$A C$ & 1.37 \\
$B C$ & 25.3 \\
Error & 0.27 \\
\hline
\end{tabular}

$$
\begin{aligned}
V= & 0.08729-0.000548 A-0.02946 B-0.1088 C \\
& +0.000002 A^{2}-0.009084 B^{2}-0.35627 C^{2} \\
& +0.000367 A B+0.000338 A C+0.2767 B C
\end{aligned}
$$

\subsection{Development of Chip Frequency Model}

4.2.1. Analysis of Variance. The analysis of variance shown in Table 6 shows that each term of the model $(A, B, A B, A C$, $B C, A^{2}$, and $C^{2}$ ) was important to describe the chip frequency due to its low $p$ value. Furthermore, the results of the model indicate a high accuracy as the $R$-sq. value was high (98.73\%).

Table 7 shows the estimated regression coefficients for the chip frequency. Consequently, the values of the coefficients were significantly different. As the $p$ values were lower than 0.05 for the linear term, this set of parameters could represent the behavior of the chip frequency. The cutting speed and depth of cut are significant to the response model at $p=0.05$. 


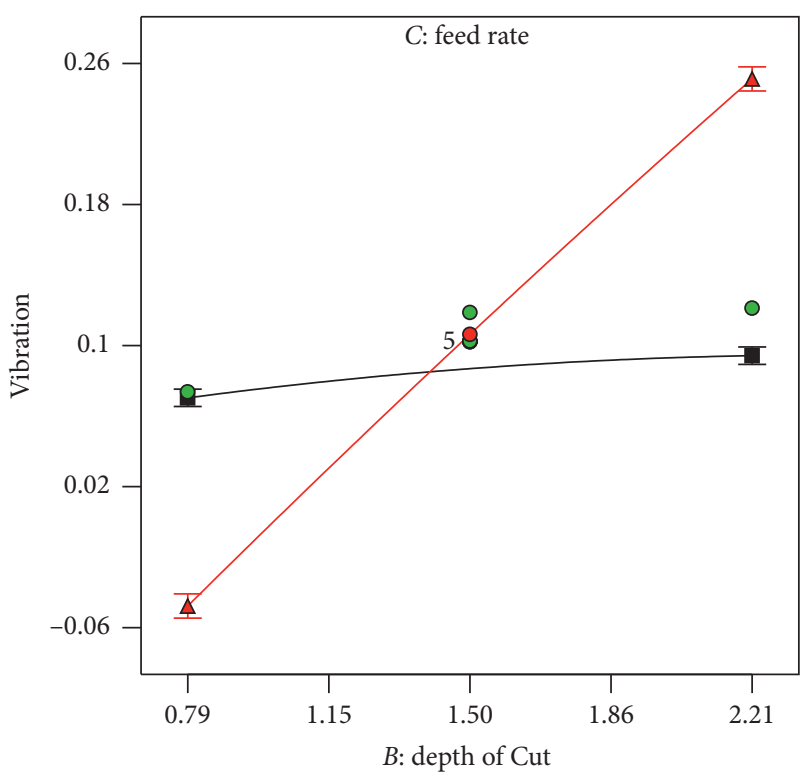

Figure 9: Interaction plot for the depth of cut vs. feed rate.

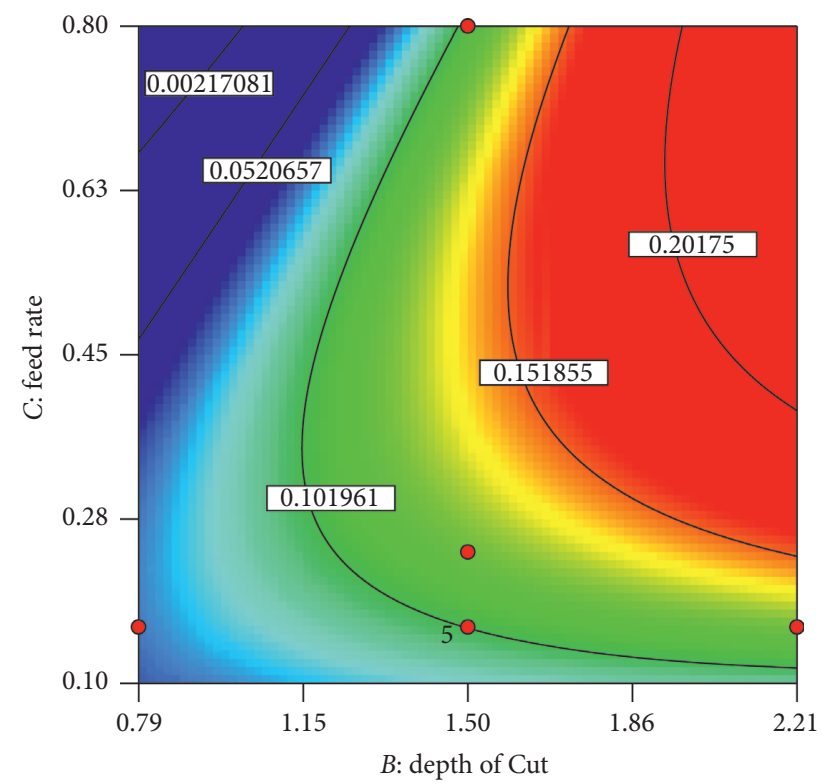

FIgURE 10: Vibration contour plots (depth of cut vs. feed rate).

4.2.2. Residual Plots for Chip Frequency. Figure 12 displays the residual plots for chip frequency against the percentage and fitted values, the frequency of the values in the dataset, and the observation index. The results were distributed randomly based on the fitted values and observation index. Moreover, the results show that the $p$ value of the residuals (0.08) was higher than 0.05 for the chip frequency. A linear relation is observed when the residuals are plotted against the percent values.

Table 8 indicates the contribution of each significant parameter and their combination. The cutting speed had the highest contribution for chip frequency, followed by the combination of cutting speed and depth of cut, feed rate, cutting speed and feed rate, and feed rate.

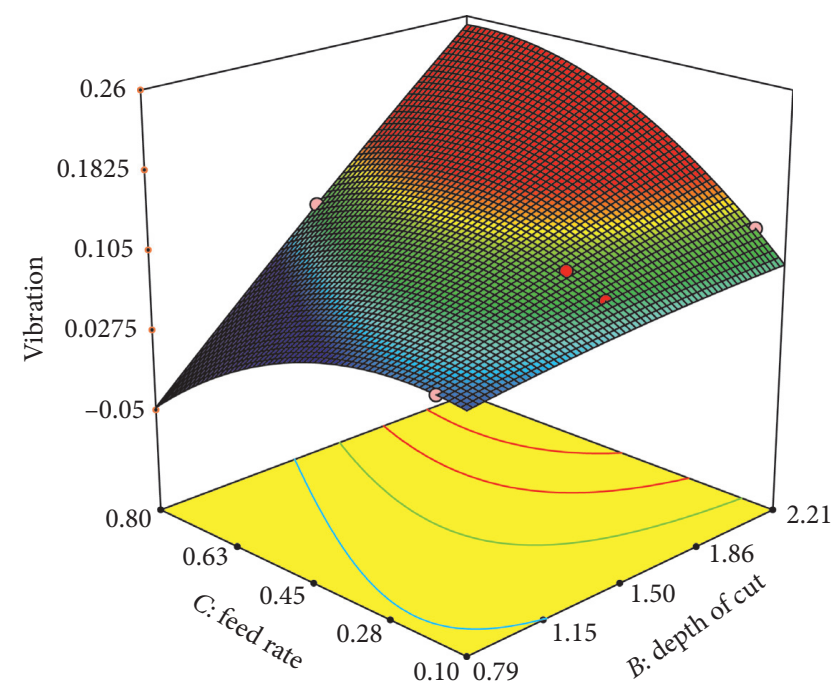

FIGURE 11: Surface plot for the vibration.

4.2.3. Interaction Plot for Chip Frequency. Figure 13 shows the influences of the combinations of the cutting speed and feed rate, and depth of cut and feed rate on the chip frequency. The interaction plot shows that the increase in cutting speed led to a decrease in chip frequency. By contrast, the chip frequency increased with the depth of cut.

4.2.4. Contour Plot for Chip Frequency. Figure 14 displays the chip frequency contours for all different combinations of cutting parameters. Consequently, the chip frequency increases with the feed rate and decreases with the cutting speed.

Figure 15 shows the chip frequency contours for all different combinations of cutting parameters. Consequently, increasing the depth of cut and decreasing feed rate leads to increase in the chip frequency

4.2.5. Surface Plot for Chip Frequency. Figures 16 and 17 show surface plots for chip frequency based on the combination of cutting speed and feed rate, and depth of cut and feed rate, respectively. In the first case, the target chip frequency can be achieved by decreasing the cutting speed and increasing the feed rate. Meanwhile, in the second case, the target chip frequency can be achieved by decreasing the depth of cut and increasing the feed rate.

4.2.6. Mathematical Model for Chip Frequency. The chip frequency model obtained from the procedure in the previous section is represented in the following equation:

$$
\begin{aligned}
\operatorname{chip} \text { frequency }(\mathrm{CF})= & -4277+370 A+4310 B-129460 C \\
& -0.3551 A 2-1344 B^{2}+93196 C^{2} \\
& -122 A B-365.5 A C+58962 B C .
\end{aligned}
$$


TABLe 6: Analysis of variance for chip frequency.

\begin{tabular}{|c|c|c|c|c|c|}
\hline Source & DF & Adj SS & Adj MS & $F$ value & $p$ value \\
\hline Model & 9 & 92636996 & 10293000 & 43.34 & $\leq 0.001$ \\
\hline Linear & 3 & 38823611 & 12941204 & 54.49 & $\leq 0.001$ \\
\hline$A$ & 1 & 36419987 & 36419987 & 153.35 & $\leq 0.001$ \\
\hline$B$ & 1 & 299521 & 299521 & 1.26 & 0.312 \\
\hline C & 1 & 5980997 & 5980997 & 25.18 & 0.004 \\
\hline Square & 3 & 21165821 & 7055274 & 29.71 & 0.001 \\
\hline$A^{\frac{1}{2}}$ & 1 & 12231515 & 12231515 & 51.5 & 0.001 \\
\hline$B^{2}$ & 1 & 792505 & 792505 & 3.34 & 0.127 \\
\hline$C^{2}$ & 1 & 14915918 & 14915918 & 62.81 & 0.001 \\
\hline Two-way interaction & 3 & 28164921 & 9388307 & 39.53 & 0.001 \\
\hline$A B$ & 1 & 18559860 & 18559860 & 78.15 & $\leq 0.001$ \\
\hline$A C$ & 1 & 5433264 & 5433264 & 22.88 & 0.005 \\
\hline$B C$ & 1 & 4171797 & 4171797 & 17.57 & 0.009 \\
\hline Error & 5 & 1187474 & 237495 & - & - \\
\hline Pure error & 4 & 360499 & 90125 & - & - \\
\hline Total & 14 & 93824469 & - & - & - \\
\hline Model summary & $S(487.334)$ & $R$-sq. $(98.73 \%)$ & $R$-sq. (adj) $(96.46 \%)$ & - & - \\
\hline
\end{tabular}

TABLE 7: Estimated regression coefficients for chip frequency.

\begin{tabular}{lcc}
\hline Term & Coef. & $p$ value \\
\hline Constant & -3144 & 0.041 \\
$A$ & -4963 & 0.033 \\
$B$ & 8211 & 0.037 \\
$C$ & -991 & 0.052 \\
$A^{2}$ & -1997 & 0.001 \\
$B^{2}$ & -677 & 0.127 \\
$C^{2}$ & 11417 & 0.001 \\
$A B$ & -6495 & $\leq 0.001$ \\
$A C$ & -9595 & 0.005 \\
$B C$ & 14652 & 0.009 \\
\hline
\end{tabular}
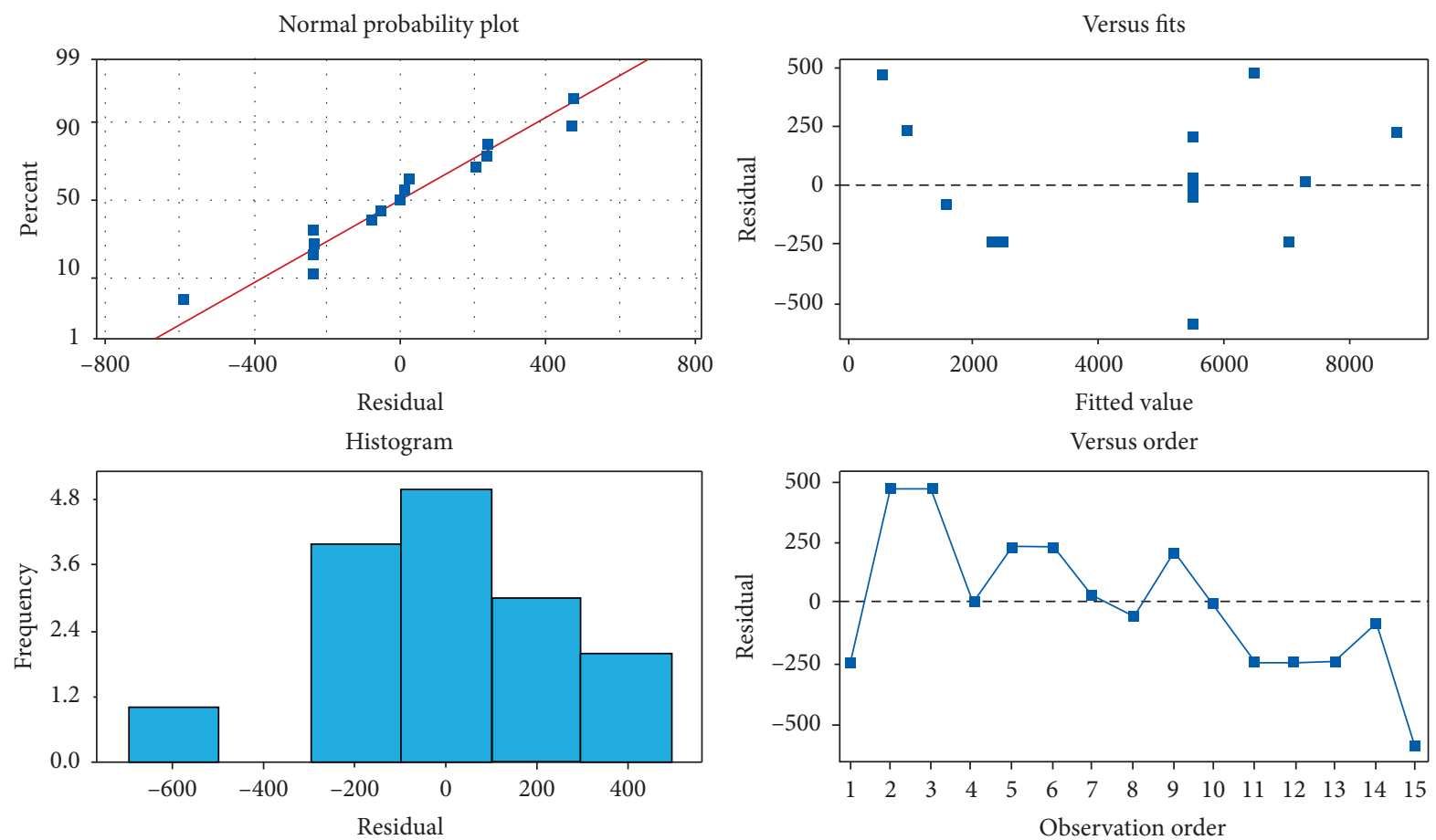

Figure 12: Residual plots for chip frequency (Hz). 
TABle 8: Percentage contribution for chip frequency.

\begin{tabular}{lc}
\hline Item & Percentage contribution \\
\hline$A$ & 50.8 \\
$B$ & 0 \\
$C$ & 8.34 \\
$A B$ & 25.9 \\
$A C$ & 7.57 \\
$B$ C & 5.81 \\
Error & 1.65 \\
\hline
\end{tabular}

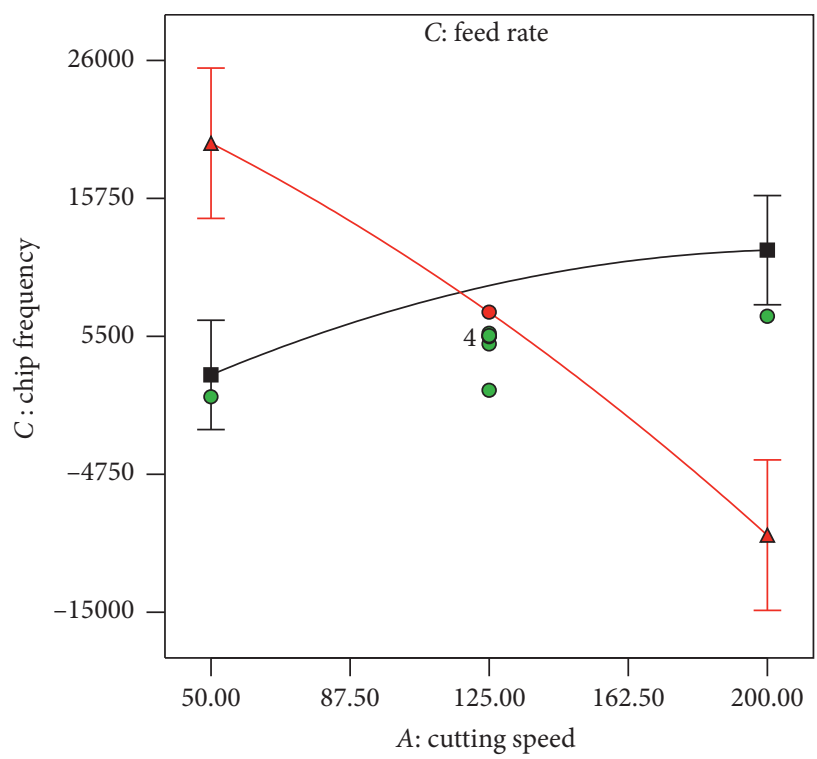

(a)

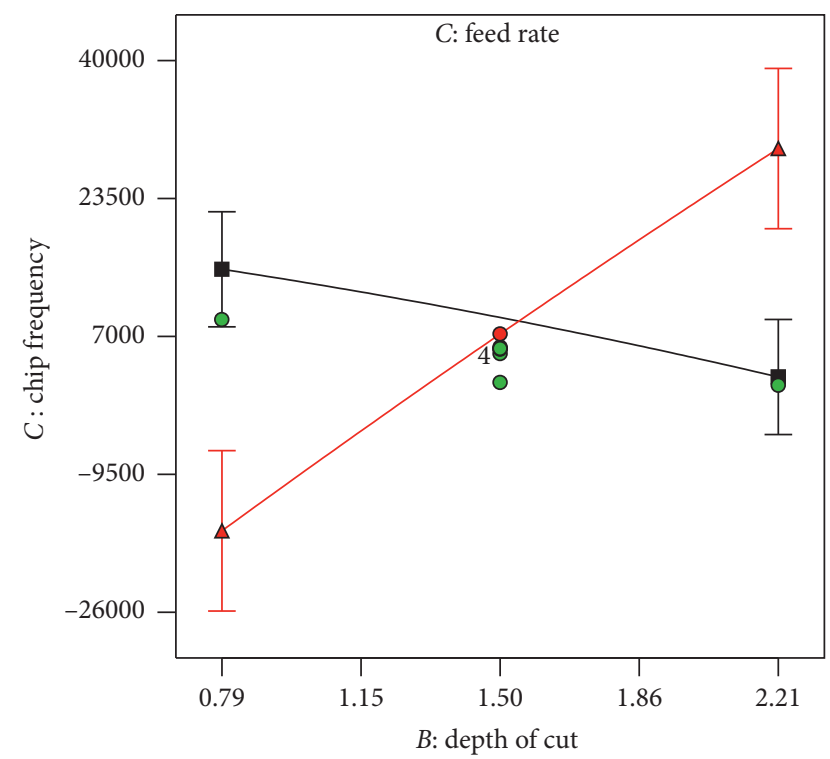

(b)

FIGURE 13: Interaction plot for chip frequency.

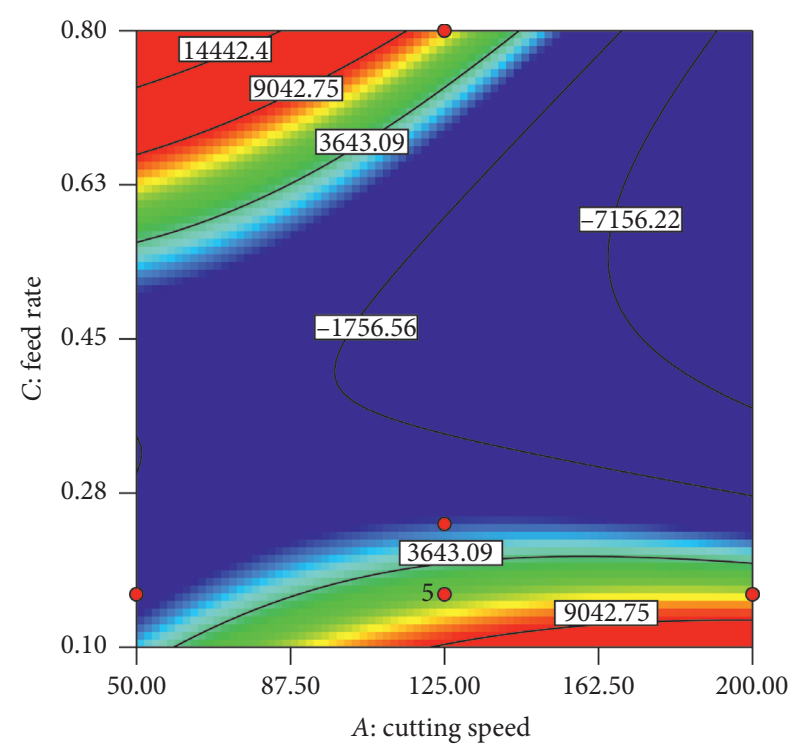

FIGURE 14: Chip frequency contour plots based on the cutting speed and feed rate.

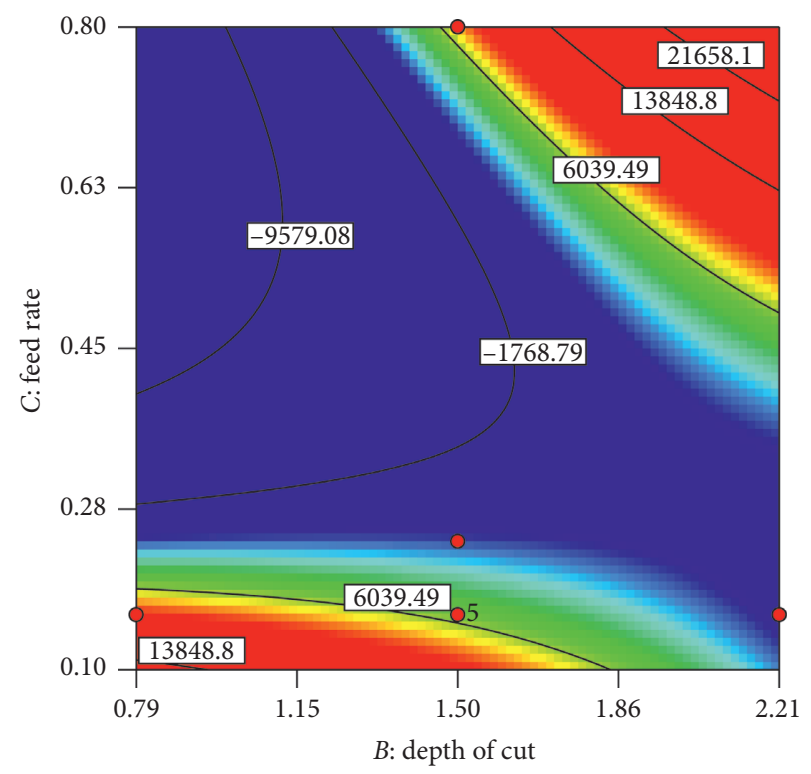

FIgURE 15: Chip frequency contour plots based on the depth of cut and feed rate. 


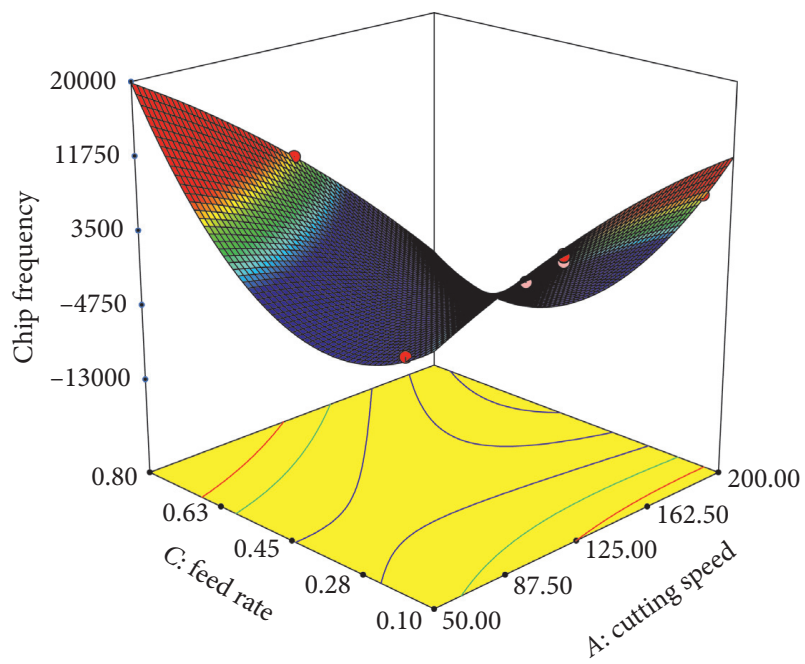

Figure 16: Surface plot of chip frequency based on the combination of cutting speed and feed rate.

4.3. Optimization of Vibration and Chip Frequency. The goal of optimization is to obtain minimum vibration and chip frequency with the assist of numerical optimization technique by modifying the turning conditions. Thus, this study will solve the optimization problem by combining the RSM vibration and chip frequency models with the tabu search (TS) and simulated annealing (SA) algorithms, which has since been very popular in the solution of optimization problems [39]. TS uses memory (called tabu list) for saving search information, which helps avoid previous solutions that have been visited. The tabu list is updated at each iteration of the TS. Due to restrictions on the tabu list, the risk of rejecting solutions which are not yet generated may occur.

Tabu solutions are therefore inspected for certain condition, known as the criteria for aspiration. If the tabu solution is better than the best objective value found so far, the tabu solution will be accepted and its move will get removed from the tabu list [40]. Like any local search method, TS has various elements to be tuned before the search process starts. Initial solution, tabu list, neighboring structure, aspiration criteria, and stopping criteria are the main elements of TS [41].

In case of a minimization problem, the general TS algorithm can be presented as shown in Algorithm 1 [41].

Simulated annealing is an approach of solving combinatorial optimization problems, and this approach points to a straight analogy in which liquids freeze and crystallize or that metals cool and anneal. Simulated annealing approach is based on the work of Metropolis et al. [42] and Kaid et al. [43] for solving combinatorial optimization problems. Basically, the change in energy of a system when it is converges to a steady "frozen" state by applying a cooling process on that system has been simulated by Metropolis's algorithm. SA explores the set of all possible solutions, minimizing the chance of being cohesive to local optima by accepting moves that may worsen the value of the objective function to escape from the local optima and move toward a new area in the solution space. A better move is always accepted. Assuming a

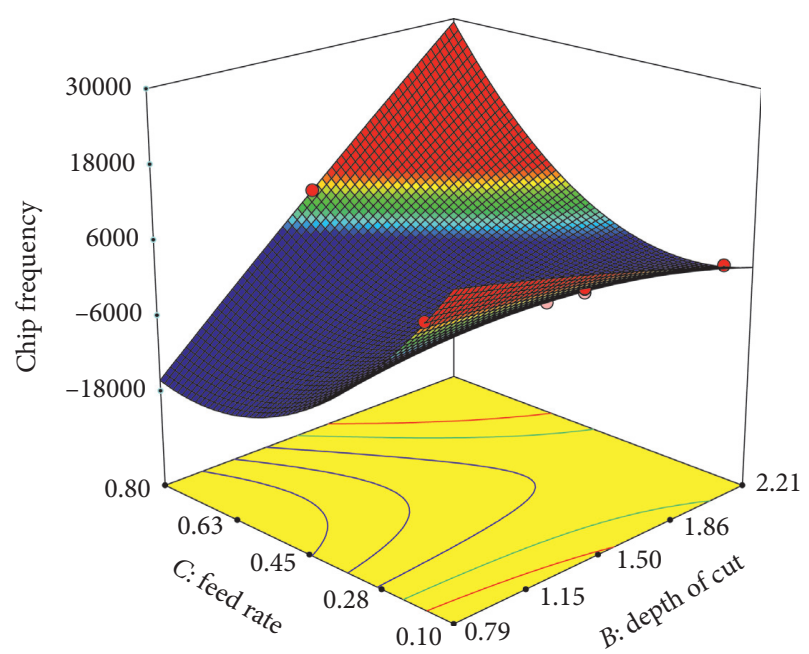

Figure 17: Surface plot of chip frequency based on the combination of depth of cut and feed rate.

minimization problem with solution space $S$, objective function $f$, and neighborhood structure $\mathrm{N}$, the general SA algorithm can be stated as shown in Algorithm 2 [43, 44].

The optimization of vibration and chip frequency will be formulated in the standard mathematical formats.

Vibration"

(i) Find: $A$ (cutting speed), $B$ (depth of cut), $C$ (feed rate)

(ii) Minimize $V(A, B, C)$

(iii) Subject to

(iv) $A_{\min } \leq A \leq A_{\max }$

(v) $B_{\min } \leq B \leq B_{\max }$

(vi) $C_{\min } \leq C \leq C_{\max }$

Chip frequency:

(i) Find: $A$ (cutting speed), $B$ (depth of cut), $C$ (feed rate)

(ii) Minimize $\mathrm{CF}(A, B, C)$

(iii) Subject to

(iv) $A_{\min } \leq A \leq A_{\max }$

(v) $B_{\min } \leq B \leq B_{\max }$

(vi) $C_{\min } \leq C \leq C_{\max }$

The proposed TS algorithm was implemented on MATLAB R2015a. A PC with Intel (R) Core (TM) i74702MQ CPU @ 2.20 GHz, 16 GB RAM, and running on Windows 10, 64-bit operating system. The parameter tuning is an important problem in the design of the TS and SA algorithms. The values of the TS and SA algorithm parameters influence its performance. For this purpose, test runs have been performed for a variety of TS and SA algorithm parameter values, and the best possible setting is selected and presented in Table 9.

By solving the optimization problem, Minitab optimizer, TS, and SA predicted the optimum vibration and chip frequency for the machining of AISI 1040 steel in the selected turning condition range. Table 10 shows the optimal 
$s=s_{0} ; \%$ Initial solution

Initialize the tabu list, medium-term and long-term memories;

Repeat

Generate a set " $A$ " of solutions;

Find best neighbor $s^{\prime}$ of $A$; \%nontabu or aspiration criterion holds

$s=s^{\prime}$

Update tabu list and aspiration conditions;

If $f(s)<f\left(s_{0}\right)$ Then $s_{0}=s$;

Until stopping criteria satisfied

Output: $s_{0}$ is the best-found solution.

Algorithm 1: TS algorithm template.

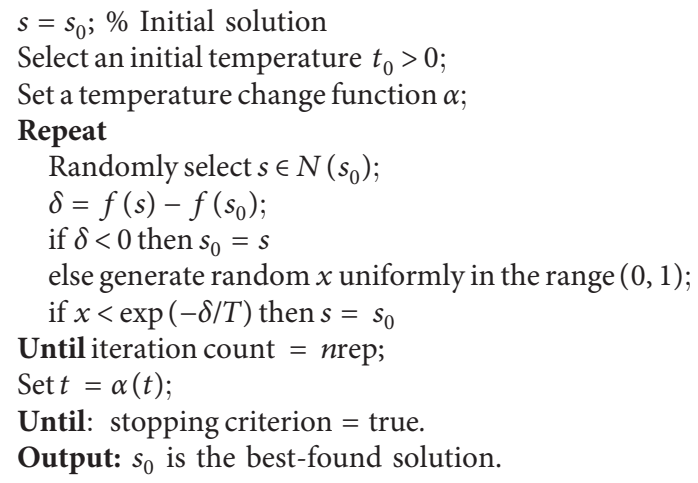

Algorithm 2: SA algorithm template.

TABle 9: Parameters setting for TS and SA.

\begin{tabular}{lcc}
\hline Metaheuristic & Parameter & Value \\
\hline & Tabu list size & 7 \\
TS & Candidate list size & 70 \\
& Number of iterations & 300 \\
\hline & Initial temperature & 200 \\
SA & Final temperature & 0.001 \\
& No. of iterations & 300 \\
& $\alpha$ & 0.9 \\
\hline
\end{tabular}

TABLE 10: Best condition for achieving the optimum vibration and chip frequency by Minitab optimizer, TS, and SA.

\begin{tabular}{lccc}
\hline Parameter & & Method & TS \\
& Minitab optimizer & 50 & SA \\
\hline Cutting speed (mm/s) & 50 & 0.79 & 50 \\
Depth of cut (mm) & 0.79 & 0.8 & 0.79 \\
Feed rate (ft./rot) & 0.8 & -0.076 & 0.8 \\
Vibration (Volt) & -0.076 & -10193 & -0.076 \\
Chip frequency (Hz) & -10193 & -10193 \\
\hline
\end{tabular}

conditions and for minimum vibration and chip frequency. In this condition, the cutting speed was $50 \mathrm{~mm} / \mathrm{s}$, depth of the cut was $0.79 \mathrm{~mm}$, and feed rate was $0.80 \mathrm{ft} / \mathrm{rot}$. The optimum vibration and chip frequency were 0.076 Volt and $10193 \mathrm{~Hz}$, respectively. In addition, Figures 18 and 19 show the final graph of MATLAB operation results for the parameter convergence curves in the vibration and chip frequency optimization.

With physical measurements, the optimum conditions predicted by the Minitab optimizer, TS, and SA were further validated. The results of the experiments with optimum 


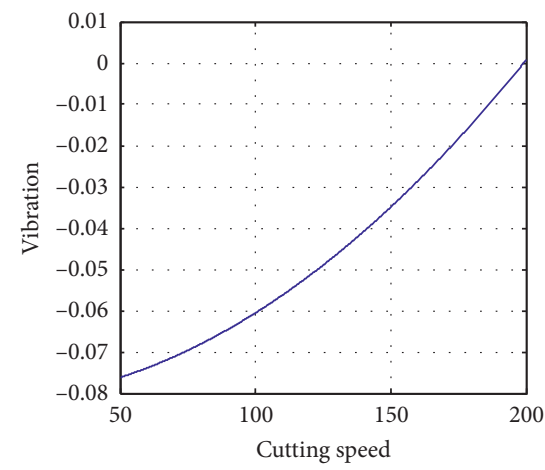

(a)

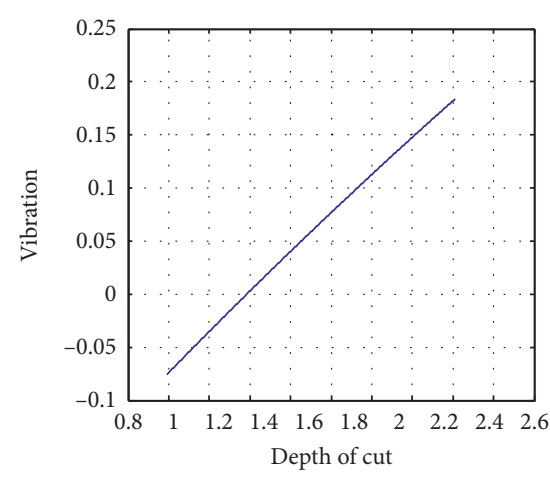

(b)

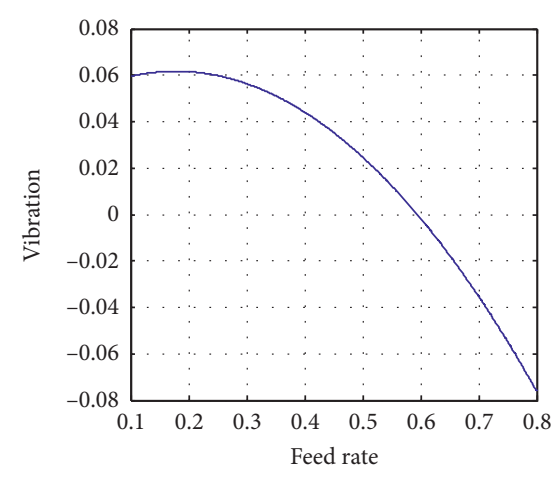

(c)

FIGURE 18: The parameter convergence curves in the vibration optimization. (a) Cutting speed. (b) Depth of cut. (c) Feed rate.

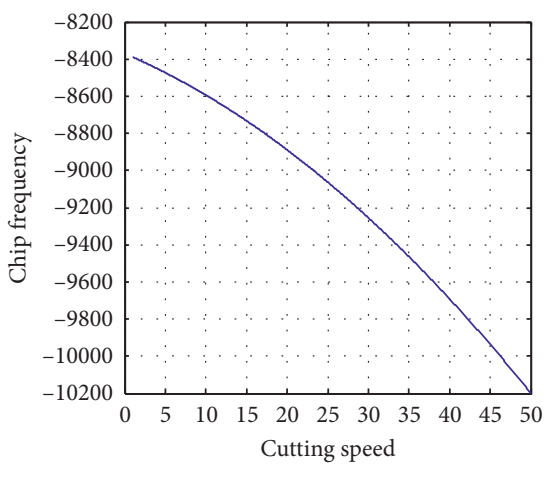

(a)

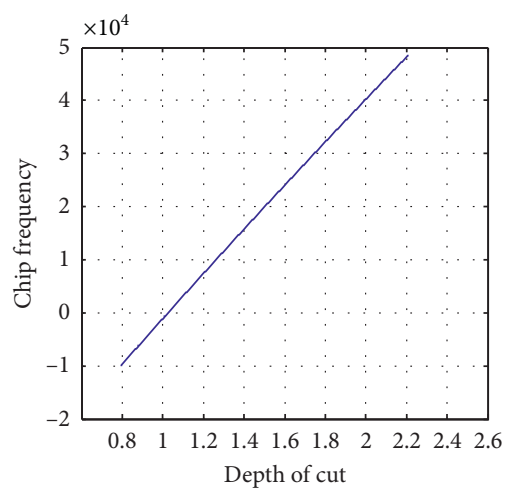

(b)

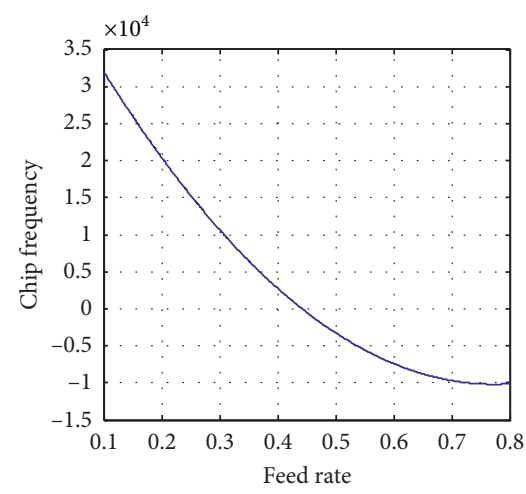

(c)

FIgURE 19: The parameter convergence curves in the chip frequency optimization. (a) Cutting speed. (b) Depth of cut. (c) Feed rate.

turning parameters for the vibration and chip frequency (as predicted by Minitab optimizer, TS, and SA) are good.

\section{Conclusion}

In this study, the RSM based on TS and SA was applied to predict the influences of key parameters, such as cutting speed, depth of cut, feed rate, vibration, and frequency, on the surface roughness. The workpiece of the experiment was made of a commercial and commonly used AISI 1040 steel, and the experiment was performed using a lathe machine Harrison M390, which has $5.5 \mathrm{~kW}$ of nominal power and $2000 \mathrm{rpm}$ of maximum spindle speed. The parameters required to achieve the optimum cutting, regarding surface roughness in a turning process, were obtained through an optimization procedure. The findings and conclusions are presented as follows:

(i) The RSM methodology combined with the design of the experiments is a useful technique for analyzing the surface roughness, which is influenced by the vibration and chip frequency of the process.

(ii) The results obtained using the RSM provided an effective, systematic, and practical method for improving the turning process.

(iii) The cutting speed, depth of cut, and feed rate were statistically associated with vibration and chip frequency. The vibration, therefore, increased when the cutting speed $(A)$ increased from 50 to $200 \mathrm{~mm} / \mathrm{s}$ or when the depth of cut $(B)$ increased from 1 to $2 \mathrm{~mm}$. Meanwhile, the chip frequency decreased when the cutting speed $(A)$ increased from 50 to $200 \mathrm{~mm} / \mathrm{s}$ and increased when the depth of cut increased from 1 to $2 \mathrm{~mm}$.

(iv) Three-dimensional surfaces generated by RSM can help the user to visualize the effects of the parameters on the surface roughness, considering the specified range.

(v) The optimization is generated from the RSM and TS and SA algorithms. The optimal conditions to minimize the vibration and chip frequency were a cutting speed of $50 \mathrm{~mm} / \mathrm{s}$, depth of the cut of $0.79 \mathrm{~mm}$, and feed rate of $0.80 \mathrm{ft} /$ rot.

\section{Data Availability}

The data used to support the findings of this study are included within the article.

\section{Conflicts of Interest}

The authors declare that there are no conflicts of interest regarding the publication of this paper. 


\section{Authors' Contributions}

Adel Al-Shayea, Fawaz M. Abdullah, and Mohammed A. Noman were responsible for the conceptualization of the study. Husam Kaid developed the software. Adel Al-Shayea, Fawaz M. Abdullah, Mohammed A. Noman, and Husam Kaid were responsible for the methodology of the study. Fawaz M. Abdullah, Mohammed A. Noman, and Husam Kaid performed the formal analysis and validated the study. Adel Al-Shayea, Fawaz M. Abdullah, and Mohammed A. Noman wrote the original draft. Adel Al-Shayea, Fawaz M. Abdullah, Mohammed A. Noman, Husam Kaid, and Emad Abouel Nasr edited and reviewed the draft. Fawaz M. Abdullah, Mohammed A. Noman, and Husam Kaid were responsible for visualization of the data and for data curation. Adel Al-Shayea supervised the study. Emad Abouel Nasr was responsible for acquisition of the fund. All authors have read and agreed to the publication of the manuscript.

\section{Acknowledgments}

This study was supported by Researchers Supporting Project number RSP-2020/164, King Saud University, Riyadh, Saudi Arabia.

\section{References}

[1] N. Mandal, B. Doloi, B. Mondal, and R. Das, "Optimization of flank wear using Zirconia Toughened Alumina (ZTA) cutting tool: Taguchi method and Regression analysis," Measurement, vol. 44, no. 10, pp. 2149-2155, 2011.

[2] N. Fang, P. S. Pai, and S. Mosquea, "Effect of tool edge wear on the cutting forces and vibrations in high-speed finish machining of Inconel 718: an experimental study and wavelet transform analysis," The International Journal of Advanced Manufacturing Technology, vol. 52, no. 1-4, pp. 65-77, 2011.

[3] A. Siddhpura and R. Paurobally, "A review of flank wear prediction methods for tool condition monitoring in a turning process," The International Journal of Advanced Manufacturing Technology, vol. 65, no. 1-4, pp. 371-393, 2013.

[4] M. Wiercigroch and E. Budak, "Sources of nonlinearities, chatter generation and suppression in metal cutting," Philosophical Transactions of the Royal Society of London. Series A: Mathematical, Physical and Engineering Sciences, vol. 359, no. 1781, pp. 663-693, 2001.

[5] M. N. Hamdan and A. E. Bayoumi, "An approach to study the effects of tool geometry on the primary chatter vibration in orthogonal cutting," Journal of Sound and Vibration, vol. 128, no. 3, pp. 451-469, 1989.

[6] D. E. Dimla Sr., "The correlation of vibration signal features to cutting tool wear in a metal turning operation," The International Journal of Advanced Manufacturing Technology, vol. 19, no. 10, pp. 705-713, 2002.

[7] D. E. Dimla Sr., "The impact of cutting conditions on cutting forces and vibration signals in turning with plane face geometry inserts," Journal of Materials Processing Technology, vol. 155-156, pp. 1708-1715, 2004.

[8] I. Asiltürk and H. Akkuş, "Determining the effect of cutting parameters on surface roughness in hard turning using the Taguchi method," Measurement, vol. 44, no. 9, pp. 1697-1704, 2011.

[9] L. Dan and J. Mathew, "Tool wear and failure monitoring techniques for turning-a review," International Journal of
Machine Tools and Manufacture, vol. 30, no. 4, pp. 579-598, 1990.

[10] S. B. Rao, "Tool wear monitoring through the dynamics of stable turning," Journal of Engineering for Industry, vol. 108, no. 3, pp. 183-190, 1986.

[11] E.J. Weller, H. M. Schrier, and B. Weichbrodt, "What sound can be expected from a worn tool?" Journal of Engineering for Industry, vol. 91, no. 3, pp. 525-534, 1969.

[12] S. M. Pandit and S. Kashou, "A data dependent systems strategy of on-line tool wear sensing," Journal of Engineering for Industry, vol. 104, no. 3, pp. 217-223, 1982.

[13] S. M. Pandit and S. Kashou, "Variation in friction coefficient with tool wear," Wear, vol. 84, no. 1, pp. 65-79, 1983.

[14] C. Y. Jiang, Y. Z. Zhang, and H. J. Xu, "In-process monitoring of tool wear stage by the frequency band-energy method," CIRP Annals, vol. 36, no. 1, pp. 45-48, 1987.

[15] B. Sick, "On-line and indirect tool wear monitoring in turning with artificial neural networks: a review of more than a decade of research," Mechanical Systems and Signal Processing, vol. 16, no. 4, pp. 487-546, 2002.

[16] D. E. Dimla Sr. and P. M. Lister, "On-line metal cutting tool condition monitoring," International Journal of Machine Tools and Manufacture, vol. 40, no. 5, pp. 739-768, 2000.

[17] S. V. Kamarthi and S. Pittner, "Fourier and wavelet transform for flank wear estimation-a comparison," Mechanical Systems and Signal Processing, vol. 11, no. 6, pp. 791-809, 1997.

[18] R. G. Silva, R. L. Reuben, K. J. Baker, and S. J. Wilcox, "Tool wear monitoring of turning operations by neural network and expert system classification of a feature set generated from multiple sensors," Mechanical Systems and Signal Processing, vol. 12, no. 2, pp. 319-332, 1998.

[19] N. Ambhore, D. Kamble, and S. Chinchanikar, "evaluation of cutting tool vibration and surface roughness in hard turning of AISI 52100 steel: an experimental and ANN approach," Journal of Vibration Engineering \& Technologies, vol. 8, no. 3, pp. 455-462, 2020.

[20] M. A. Sofuoğlu, F. H. Çakır, S. Gürgen, S. Orak, and M. C. Kuşhan, "Experimental investigation of machining characteristics and chatter stability for Hastelloy-X with ultrasonic and hot turning," The International Journal of Advanced Manufacturing Technology, vol. 95, no. 1-4, pp. 83-97, 2018.

[21] F. H. Çakır, M. A. Sofuoğlu, and S. Gürgen, "Machining of Hastelloy-X based on finite element modelling," Advanced Engineering Forum, vol. 30, pp. 1-7, 2018.

[22] M. A. Sofuoğlu, F. H. Çakır, S. Gürgen, S. Orak, and M. C. Kuşhan, "Numerical investigation of hot ultrasonic assisted turning of aviation alloys," Journal of the Brazilian Society of Mechanical Sciences and Engineering, vol. 40, no. 3, p. 122, 2018.

[23] S. Gürgen, F. H. Çakır, M. A. Sofuoğlu, S. Orak, M. C. Kuşhan, and $\mathrm{H}$. Li, "Multi-criteria decision-making analysis of different non-traditional machining operations of Ti6 $\mathrm{Al}_{4} \mathrm{~V}$," Soft Computing, vol. 23, no. 13, pp. 5259-5272, 2019.

[24] A. K. Parida, P. V. Rao, and S. Ghosh, "Performance of textured tool in turning of Ti-6Al-4V alloy: numerical analysis and experimental validation," Journal of the Brazilian Society of Mechanical Sciences and Engineering, vol. 42, no. 5, pp. 1-14, 2020.

[25] S. Gürgen, D. Tali, and M. C. Kushan, "an investigation on surface roughness and tool wear in turning operation of Inconel 718," Journal of Aerospace Technology and Management, vol. 11, 2019.

[26] A. Şahinoğlu and M. Rafighi, "Optimization of cutting parameters with respect to roughness for machining of hardened 
AISI 1040 steel,” Materials Testing, vol. 62, no. 1, pp. 85-95, 2020.

[27] T. Haque, S. Kumar, D. Upadhaya, M. Barman, and A. Mukhopadhyay, "Optimization of multiple roughness characteristics for turning of AISI 1040 steel under different cutting conditions," International Journal of Engineering and Technologies, vol. 10, pp. 1-10, 2017.

[28] D. B. Prakash and G. Krishnaiah, "Optimization of process parameters using AHP and VIKOR when turning AISI 1040 steel with coated tools," International Journal of Mechanical Engineering and Technology (IJMET), vol. 8, no. 1, pp. 241248, 2017.

[29] P. N. L. Pavani, C. L. V. R. S. V. Prasad, and K. Ramji, "Experimental study and optimization of machining parameters in turning of AISI 1040 steel with micro-grooved WC cutting tools," Engineering Journal, vol. 21, no. 4, pp. 155-169, 2017.

[30] S. S. Nair, T. Ramkumar, M. S. Kumar, and F. Netto, "Experimental investigation of dry turning of AISI 1040 steel with TiN coated insert," Engineering Research Express, vol. 1, no. 2, Article ID 025038, 2019.

[31] B. S. Kumar, G. Padmanabhan, and P. V. Krishna, "Optimisation of turning AISI 1040 steel with extreme pressure additive in vegetable oil based cutting fluids," International Journal of Automotive and Mechanical Engineering, vol. 14, no. 2, pp. 4285-4297, 2017.

[32] R. T. Johnson, P. A. Parker, D. C. Montgomery, A. D. Cutler, P. M. Danehy, and R. D. Rhew, "Design strategies for response surface models for the study of supersonic combustion," Quality and Reliability Engineering International, vol. 25, no. 3, pp. 365-377, 2009.

[33] V. N. Gaitonde, S. R. Karnik, L. Figueira, J. Paulo Davim, and H. Materials, "Machinability investigations in hard turning of AISI D2 cold work tool steel with conventional and wiper ceramic inserts," International Journal of Refractory Metals and Hard Materials, vol. 27, no. 4, pp. 754-763, 2009.

[34] İ. Asiltürk and S. Neşeli, "Multi response optimisation of CNC turning parameters via Taguchi method-based response surface analysis," Measurement, vol. 45, no. 4, pp. 785-794, 2012.

[35] C. Camposeco-Negrete, "Optimization of cutting parameters for minimizing energy consumption in turning of AISI 6061 T6 using Taguchi methodology and ANOVA," Journal of Cleaner Production, vol. 53, pp. 195-203, 2013.

[36] R. K. Bhushan, "Optimization of cutting parameters for minimizing power consumption and maximizing tool life during machining of $\mathrm{Al}$ alloy $\mathrm{SiC}$ particle composites," Journal of Cleaner Production, vol. 39, pp. 242-254, 2013.

[37] D. B. Prakash, D. G. Krishnaiah, and N. V. S. Shankar, "Optimization of process parameters using Taguchi techniques when turning AISI 1040 steel with coated tools," International Journal of Mechanical Engineering and Technology (IJMET), vol. 7, no. 6, pp. 114-122, 2016.

[38] G. T. Smith, Cutting Tool Technology: Industrial Handbook, Springer Science \& Business Media, Berlin, Germany, 2008.

[39] F. Glover, "Tabu search-part II," ORSA Journal on Computing, vol. 2, no. 1, pp. 4-32, 1990.

[40] E.-G. Talbi, Metaheuristics: From Design to Implementation, John Wiley \& Sons, Hoboken, NJ, USA, 2009.

[41] I. Alharkan, M. Saleh, M. A. Ghaleb, H. Kaid, A. Farhan, and A. Almarfadi, "Tabu search and particle swarm optimization algorithms for two identical parallel machines scheduling problem with a single server," Journal of King Saud University - Engineering Sciences, vol. 32, no. 5, pp. 330-338, 2020.
[42] N. Metropolis, A. W. Rosenbluth, M. N. Rosenbluth, A. H. Teller, and E. Teller, "Equation of state calculations by fast computing machines," The Journal of Chemical Physics, vol. 21, no. 6, pp. 1087-1092, 1953.

[43] H. Kaid, I. Alharkan, A. Ghaleb, and M. A. Ghaleb, "Metaheuristics for identical parallel machines scheduling to minimize mean tardiness," in Proceedings of the 2015 International Conference on Industrial Engineering and Operations Management (IEOM), pp. 1-6, Dubai, UAE, March 2015.

[44] C. R. Reeves, Modern Heuristic Techniques for Combinatorial Problems, John Wiley \& Sons, Hoboken, NJ, USA, 1993. 